
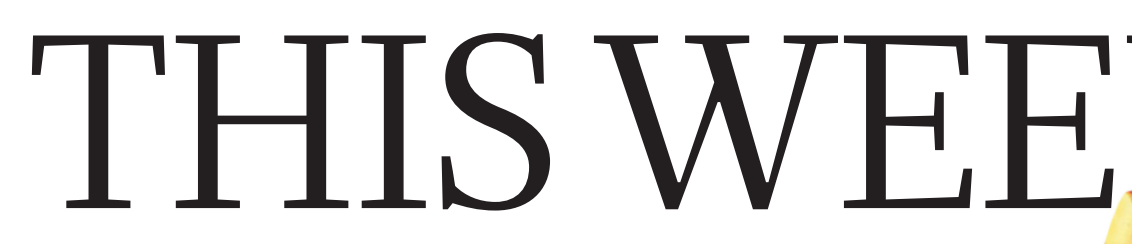

EDITORIALS

WORLD VIEW Invest to energize West African research capacity $\mathbf{p . 7}$
LIKE! Social network helps botanists to identify unknown sundew p.8
FOSSIL FIND Lizards of the Caribbean have endless sequels p.9

\title{
Trial and triumph
}

\section{The success of an Ebola vaccine trial shows that clinical trials can be done under the difficult field conditions of an epidemic - if there is enough political and regulatory will.}

$\mathrm{T}$ This is a big week in the fight against Ebola: a clinical trial of an Ebola vaccine in Guinea has reported a promising outcome. It is fantastic news - even the most cautious disease experts are hopeful that a corner has been turned.

What now? In a special collection of articles this week, Nature analyses the vaccine breakthrough and looks more broadly at the prospects for future control of epidemic threats. It is not all good news, and there are bound to be setbacks, but those who value the role of research in improving human welfare - and those who argue for broader recognition of that role among policymakers - can now walk a little taller.

Make no mistake: conducting an efficacy trial of a vaccine or a drug during an epidemic is difficult, to put it mildly. In the past, delays in getting regulatory approval for trials meant that outbreaks were usually over before the trial even started, so drugs and vaccines needed to treat the outbreak, or future ones, could not be tested.

Running a clinical efficacy trial in the arduous field conditions of an epidemic zone is no mean feat either. Yet against the odds, an international team of researchers not only did just that, but also showed that one shot of the vaccine had $100 \%$ efficacy - none of those vaccinated at the start of the trial developed Ebola ten days after receiving the vaccine (A. M. Henao-Restrepo et al. Lancet http://dx.doi.org/10.1016/S0140-6736(15)61117-5;2015).

That such a vaccine could be clinically tested - a process that usually takes years - in a short space of time and without the facilities of a sophisticated research hospital must rewrite the rules for how drug trials for infectious-disease threats are conducted. Faced with the urgency of Ebola, international collaborations of scientists, regulators, pharmaceutical companies and non-governmental organizations - and, to its credit, the World Health Organization, which had a leading role - pulled together with unprecedented speed to push vaccines and drugs through testing and into field trials.

Roll-out of the vaccine to more people will provide data to confirm its effectiveness. But by vaccinating the families, friends, health-care workers and others who come into contact with infected people, Ebola outbreaks could be stopped in their tracks - the same strategy that was used to eradicate smallpox in the 1970s. This means that this vaccine can, in principle, be deployed immediately to help to end the Ebola epidemic in West Africa. As aptly conveyed by the trial's French name, 'Ebola, ça suffit!' ('Ebola, that's enough!'), it is time to finish the job.

The job remains, because even if Ebola has faded from the headlines, it is far from over. Eighteen months after it began, the epidemic continues to cause 20-30 cases a week. It could flare up at any time or spread to as-yet-unaffected countries in the region, taking the situation back to square one. Although vaccines will need to be developed against the four other species of Ebola virus, the efficacy of this vaccine against the Zaire species - if confirmed - means that never again should an Ebola epidemic occur on the same scale as in West Africa.

\section{Driving test}

\section{'Gene drive' techniques have the potential to alter whole populations. Regulators must catch up.}

$\mathrm{L}$ ast year, researchers and policy experts expressed concerns about a - then hypothetical - way to use cutting-edge genetic techIniques to rapidly alter entire populations of plants or animals. Such a technique, called a gene drive, could lead to unanticipated ecological consequences, they cautioned (K. A. Oye et al. Science $345,626-628 ; 2014)$. The authors discussed safety guidelines, made general policy recommendations, and met with some criticism: why raise alarm over a technique that did not yet exist?

Less than a year later, it did exist. Two groups have now published examples of gene drives engineered using CRISPR, a versatile and relatively easy system that allows researchers to make changes to genomes with pinpoint precision (see page 16). Crucially, it enabled a designated mutation to copy itself from one chromosome in a pair to the other, ensuring that it was passed to offspring and allowing it to spread rapidly through a population (V. M. Gantz and E. Bier Science 348, 442-444 (2015) and J. E. DiCarlo et al. Preprint at http://doi.org/6k2; 2015).

Engineering a lab animal or agricultural crop is one thing. Wielding the power to alter an entire wild population is quite another. The process understandably raises concern. But it could hold great benefit: mosquitoes could be tweaked so that they cannot carry malaria, or an endangered species could be saved by wiping out an invasive competitor.

Last week, the debate gained momentum when the US National Academy of Sciences held its first meeting to evaluate the potential benefits and risks of gene drives. As is often the case by the time such controversies start to attract mainstream attention, specialist researchers have been thrashing out the issue for years. These discussions have already produced various sets of guidelines on the use of gene drives, and the academy and others should use this literature as a starting point.

What is new is the advent of CRISPR. This adds extra dimensions to the debate, because it makes gene drives much easier and could dramatically accelerate the timeline for a potential release - accidental or intentional. Researchers and funding agencies should take note, and efforts to understand the ecological consequences of a gene drive should be made an urgent priority. Regulators and the wider world need to keep pace with the rapid development of CRISPR technology, and there is little time to waste. 